\title{
Lung adenocarcinoma presenting as obstructive jaundice: a case report and review of literature Stephanos Pericleous ${ }^{1}$, Samrat Mukherjee ${ }^{2}$ and Robert R Hutchins*2
}

\begin{abstract}
Address: ${ }^{1}$ Department of HPB Surgery, Imperial College, Hammersmith Hospital campus, Du Cane Road, London, UK and ${ }^{2}$ Department of HPB Surgery, Royal London Hospital, Whitechapel, London, UK
\end{abstract}

Email: Stephanos Pericleous - s.pericleous@imperial.ac.uk; Samrat Mukherjee - samrat.mukherjee@rwh-tr.nhs.uk; Robert R Hutchins* - robert.hutchins@bartsandthelondon.nhs.uk

* Corresponding author

Published: II November 2008

World Journal of Surgical Oncology 2008, 6:120 doi:10.1186/1477-7819-6-120

This article is available from: http://www.wjso.com/content/6/1/120

(c) 2008 Pericleous et al; licensee BioMed Central Ltd.

This is an Open Access article distributed under the terms of the Creative Commons Attribution License (http://creativecommons.org/licenses/by/2.0), which permits unrestricted use, distribution, and reproduction in any medium, provided the original work is properly cited.
Received: 19 April 2008
Accepted: II November 2008

\begin{abstract}
Background: Lung cancer is known to metastasize to the pancreas with several case reports found in the literature, however, most patients are at an advanced stage and receive palliative treatment.

Case presentation: We describe the case of a 56 year old male patient who presented with a picture of obstructive jaundice. Investigations revealed an obstructing lesion in the pancreas and a further lesion in the lung with benign appearances. The patient underwent a pancreatectomy and, unexpectedly, the histology of the resected specimen demonstrated metastatic adenocarcinoma of bronchogenic origin. He was referred to a cardiothoracic team who proceeded to resect the patient's thoracic lesion before administration of adjuvant chemotherapy. The patient was reviewed 18 months post operatively and remains symptom free with no clinical or radiological evidence of recurrence. We were unable to identify any previous case reports (of lung adenocarcinoma) with such a presentation which were ultimately treated with resection of both lesions.

Conclusion: Similar situations are bound to arise again in the future and we believe that this report could demonstrate that there is a case for aggressive surgical management in a highly selected group of patients: those with NSCLC and a synchronous solitary pancreatic deposit.
\end{abstract}

\section{Background}

That a variety of malignant tumours can metastasise to the pancreas is well documented. Several case reports have reported patients with lung cancer whose clinical presentation was that of obstructive jaundice [1].

Most patients presenting in this manner are at an advanced stage with widespread disease, and are usually managed symptomatically. This generally involves palliative chemotherapy and/or radiotherapy coupled with other measures to relieve the biliary obstruction such as biliary stent insertion. In the few cases where operative intervention is considered, it is usually limited to a biliary bypass to relieve the jaundice.

We describe an unusual presentation where an adenocarcinoma of the lung with a synchronous solitary metastatic deposit in the pancreas (not visible on CT) was treated with operative resection of both lesions. The uniqueness of this case is enhanced by the fact that both lesions were identified preoperatively although their nature was not. 


\section{Case presentation}

A 56 year old male lawyer presented to his local hospital complaining of a recent change in his urine colour (to bright orange) and general malaise. The patient suffered from moderate bronchiectasis and asthma for which he took inhalers (fluticasone propionate, salmeterol and ipratropium bromide). He was also known to be hypertensive (controlled on diltiazem) and suffered from severe eczema. He had never been a smoker but his daily consumption of alcohol amounted to 1.5 bottles of wine.

Initial workup revealed deranged liver function tests and relevant tumour markers were raised (Ca 19-9 181 kU/l, CEA $25.8 \mu \mathrm{g} / \mathrm{l}$ ). A subsequent abdominal ultrasound showed biliary dilatation to the level of the pancreas. This was confirmed on an MRCP. However CT (64 slice fine cut spiral pancreas protocol CT) and MRI examinations failed to reveal any pancreatic mass (figure 1). An ERCP which followed confirmed the lower CBD stricture with features of external compression and a plastic biliary stent was inserted.

The patient was then referred to our unit for further treatment. The working diagnosis at this stage was a pancreatic tumour and the patient underwent staging with a view to a pancreatic resection. Unusually, as part of the initial workup, the patient had had a CT of his thorax, showing a right lung lesion, thought to be benign, on a background of known chronic respiratory disease (figure 2). A FDG-

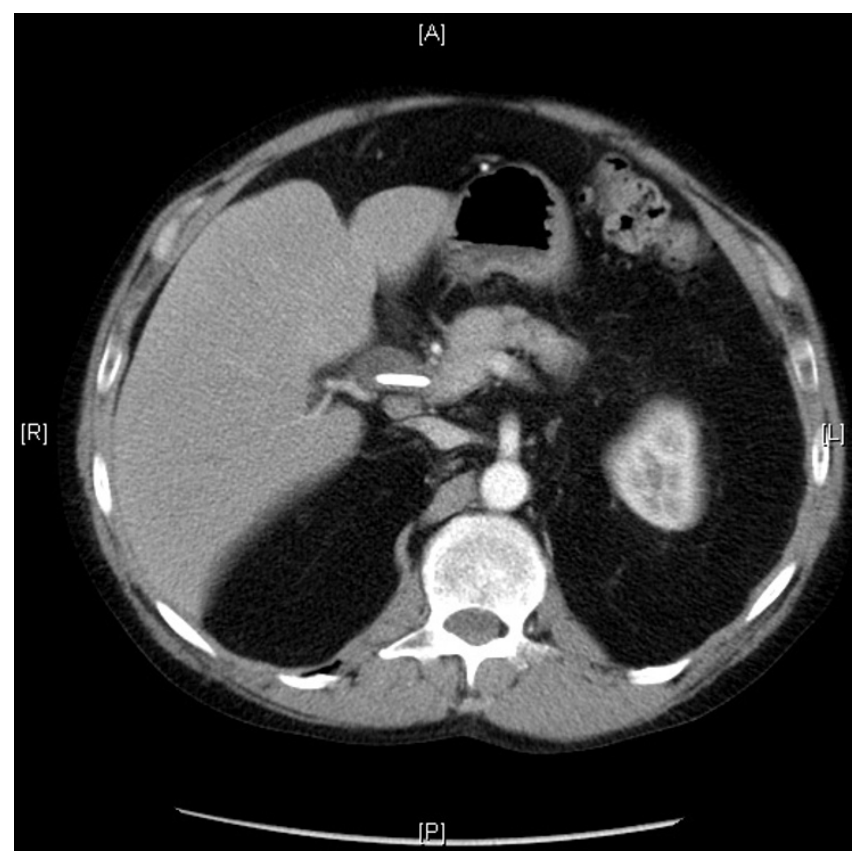

Figure I

CT scan abdomen. Stent visible in bile duct.

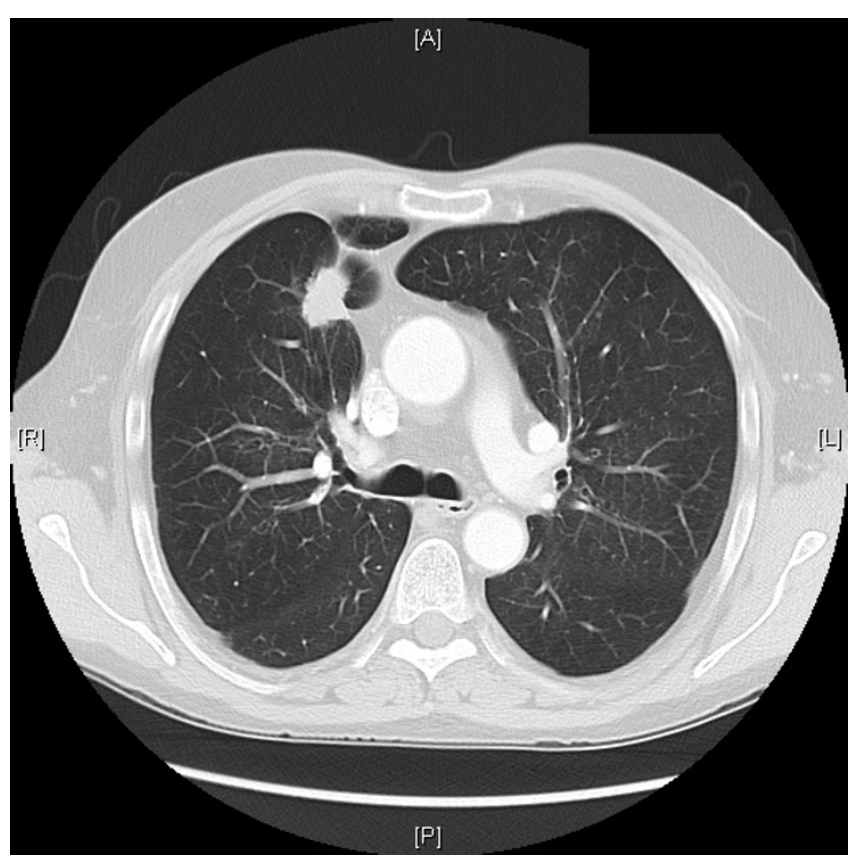

Figure 2

CT scan chest. Lesion in the right lung.

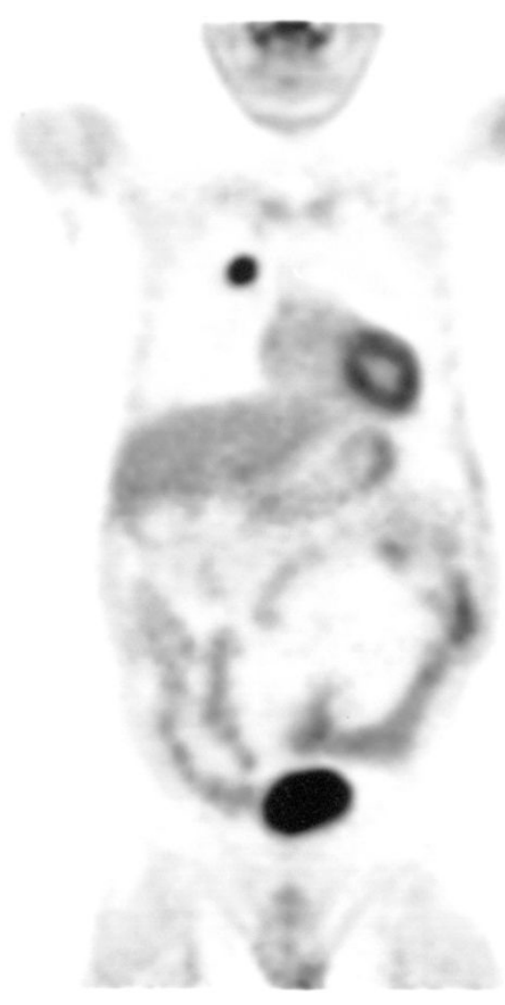

Figure 3

FDG PET scan. Lesion in the right lung. 
PET scan was performed to delineate the lung lesion further (figure 3). This scan was reported as positive, thus raising the possibility of:

- A lung primary with pancreatic metastasis

- Synchronous pancreatic and lung primaries

- A pancreatic primary with lung metastasis

CT guided biopsy of the lung lesion was performed, the histology of which showed reactive changes but no evidence of malignancy. As such and in view of the patient's background of respiratory disease the PET scan was interpreted as demonstrating reactive changes. Given the presentation, tumour markers, imaging appearances and biopsy results the working diagnosis remained that of a pancreatic cancer with no evidence of metastatic disease.

The patient proceeded to a pylorus preserving pancreaticoduodenectomy (PPPD). There was no evidence of intraabdominal spread at laparotomy. The head of the pancreas contained a palpable mass. This was resected in routine fashion. The histology of the resected specimen was a single poorly differentiated adenocarcinoma (figure 4) (11 mm in maximum dimension) staining strongly positive to TTF-1 and CK7 (figure 5), and negative staining for CK20 and PSA. The tumour did not approach any of the resection margins or surfaces. Also, none of the surrounding 16 lymph nodes had any evidence of disease.

In view of the reported immunohistochemical profile, coupled with the identification of a lung lesion, the tumour was interpreted as metastatic adenocarcinoma of

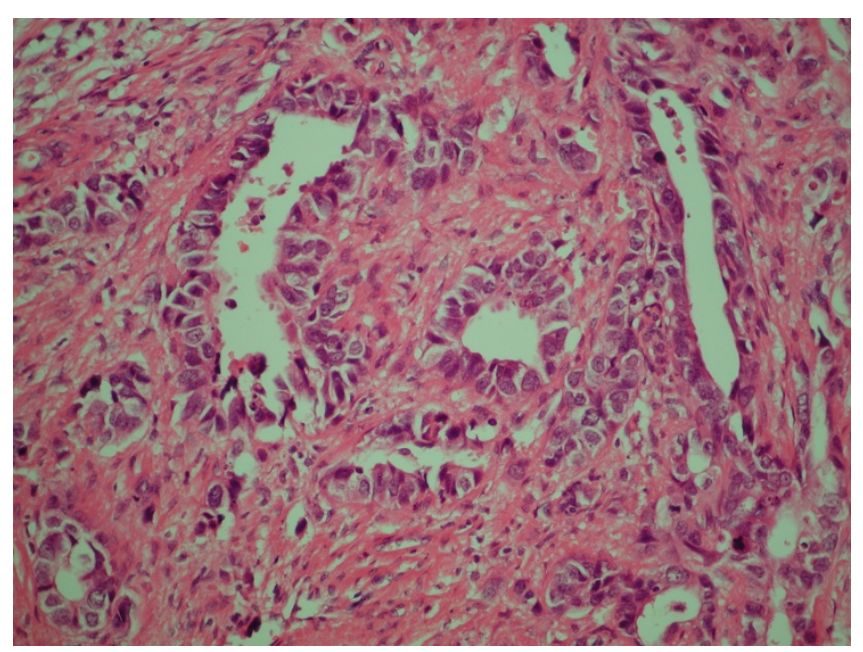

Figure 4

High magnification view of lesion resected from the pancreas (haematoxylin and eosin).

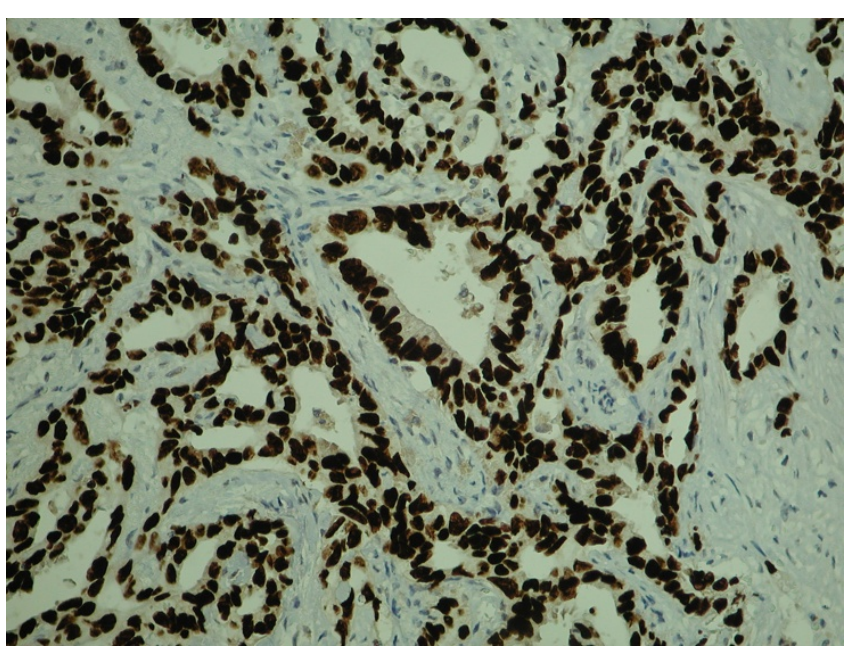

\section{Figure 5}

High magnification view of lesion resected from the pancreas (immunohistochemical staining with TTFI).

bronchial origin rather than as a primary pancreatic lesion. As a result the patient was referred to a thoracic surgeon for consideration of removal of the lung lesion. Six weeks later the patient underwent a mini thoracotomy where a $2 \times 3 \mathrm{~cm}$ lesion was identified in the medial segment of the upper lobe of the right lung. The segment was removed along with hilar and mediastinal lymph nodes for staging. Histology of this specimen reported a lung adenocarcinoma with complete excision and no lymph node involvement.

Three weeks after his lung resection the patient was started on adjuvant chemotherapy with gemcitabine and carboplatin. This regime was continued for 6 months. The patient was seen eighteen months from presentation. Clinically he remained symptom free and a follow-up CT of his chest and abdomen revealed no evidence of recurrence.

\section{Discussion}

Pancreatic cancer is one of the leading causes of cancer deaths ranking 4 th in the US and 6th in Europe [2]. However, little attention is devoted to secondary deposits of other tumours to the pancreas. Retrospective studies on pancreatectomy procedures have reported that metastatic disease represents merely $3 \%$ or so of resected malignant pancreatic masses $[3,4]$. As such they are often mistaken as pancreatic primaries and only recognised for what they truly are in retrospect on histological examination [5]. Some $98 \%$ of patients with a malignant process who present with obstructive jaundice will do so as a result of a primary pancreatic cancer [6]. On the other hand, autopsy statistics suggest that the pancreas is a more fre- 
quent site for metastatic disease, albeit on a subclinical scale. The incidence of secondary pancreatic tumours is up to $16 \%$ of autopsy studies [7], with a wide variation of primary cancers responsible. Patients who present with a clinical picture which relates directly to disease in the pancreas at presentation will tend to do so with the symptoms of obstructive jaundice or pancreatitis [8]. More often than not these patients prove to have advanced disease which is only amenable to palliative treatment.

Lung cancer metastasizes to many sites, but most frequently to bone, the liver and the adrenal glands $[9,10]$. Approximately one third of patients will present with symptoms relating to extra thoracic spread [10]. The pancreas is considered to be an infrequent target to which lung cancer will metastasize to. Figures are reported in the range of $0-12 \%$ [11-13]. The majority of those which do are of SCLC histological subtype [14]. Rarer still, at presentation, is for lung cancer to present with a clinical picture of jaundice due to synchronous metastatic adenocarcinoma [1]. In those cases where it does, this is more likely to be due to widespread hepatic disease than to extrahepatic biliary obstruction [15]. A larger subgroup of patients with lung cancer will develop a metachronous pancreatic metastasis, which will usually be identified on follow-up investigations. One recent case report published in March 2008 reports the first case of lung adenocarcinoma with a metachronous isolated deposit in the pancreas and no evidence of other disease. This case was treated with biliary stenting and palliative chemotherapy [16].

Of secondary deposits discovered in the pancreas, lung cancer makes up (along with renal cell carcinoma, breast and gastric cancer) a high percentage (table 1) [7,17-36]. Indicative published figures are $14.2 \%$ (49 of 311 secondary tumours) [7], 17.0\% (18 of 108)[18] and 18.2\% (4 of 22) [17]. The large majority of cancer patients with metastatic disease to the pancreas are treated with palliative intent as patients usually present with widespread disease. Where surgery is contemplated, it is usually limited to bypass procedures in patients with obstructive jaundice. There have been reports where patients with this presentation have undergone more major procedures such as pancreatic resection[37], but this has tended to be in ignorance of the fact that the aetiology of the obstruction was of metastatic origin, as was in our case. There are several publications advocating the consideration of a pancreatic resection in selected cases. One of these is a literature review by Minni et al, where 333 cases with secondary deposits in the pancreas were reviewed. Of these, 234 had treatment information of which 150 (64.1\%) underwent pancreatic resections [3]. More than 25 different histologic types are reported $45.0 \%$ of which were renal cell, $14.7 \%$ lung, $7.5 \%$ breast and $6.6 \%$ colonic car-
Table I: Summary of world literature on pancreatic metastases from lung cancer

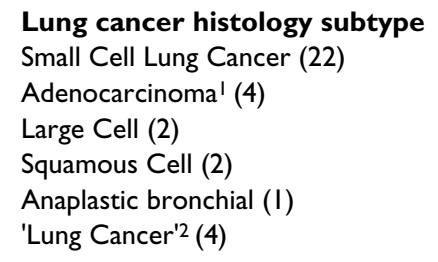

Treatment Received ${ }^{4}$

Palliative Chemotherapy (13)

Biliary stent (8)

Palliative Operation (4)

Best Supportive Care (7)

Pancreatic Resection (6)

Adjuvant Chemotherapy (2)

Exploratory laparotomy (I)

Includes our case. ${ }^{2}$ No further information from authors ${ }^{3}$ Includes patients who were identified on surveillance. ${ }^{4}$ Some patients received more than one treatment.

papers reviewed: $[6,8,16,17,19-38,47]$

cinomas. In a series of twelve patients with a variety of different metastatic tumours to the pancreas, Le Borgne et al [38], suggest that a more aggressive surgical approach should be considered, especially in patients with metachronous ampullary and pancreatic deposits from renal cell carcinomas, sarcomas and carcinoid tumours. They reported $35 \%$ survival rate at 2 years and $17 \%$ at 4 years.

Stage IV NSCLC has a poor prognosis. Median survival with best supportive care is reported as 3.6 months (range, 2.4 to 4.9 months) whilst platinum based chemotherapy regimes increase this statistic to 6.5 months (range, 4.7 to 8.5 months). This patient is alive and disease free 18 months following presentation. It is accepted practice today to consider selected patients with solitary intracranial deposits for resection [39-41]. Also it has been suggested repeatedly that a survival benefit may be achieved by surgical treatment of solitary extracranial spread of NSCLC [42-46]. The experience and information available for the surgical treatment of metastatic disease from the lung exclusively to the pancreas is very limited and few guidelines are available on the appropriate management of such cases. Most series describe treatment which, from the outset had a palliative intent. Hiotis et al [47], however, report three cases of patients with metachronous (information from personal correspondence with author) NSCLC metastatic disease to the pancreas who underwent 
pancreatectomies with curative intent. All patients developed recurrence.

\section{Conclusion}

In the majority of cancers, synchronous presentation generally carries a worse prognosis than a metachronous one. Our case is an example of a synchronous metastatic deposit resected (albeit) inadvertently. However, resection of both lesions has led to long-term disease-free survival. Therefore we believe that this report demonstrates that in selected cases consideration should be given not just to palliation but to potentially curative surgery whether it be synchronous or more likely metachronous presentation of metastatic lung cancer to the pancreas. This is very different from what has been described previously where very few operations with curative intent have been carried out, in particular on patients with NSCLC.

\section{List of abbreviations}

CT: Computed Tomography; MRCP: Magnetic Resonance Cholangiopancreatography; ERCP: Endoscopic Retrograde Cholangiopancreatography; CBD: Common Bile Duct; FDG-PET: Fluorodeoxyglucose - Positron emission tomography; NSCLC: Non-small cell lung carcinoma; TTF-1: Thyroid Transcription Factor-1; PSA: Prostate Specific Antigen; CK7, CK20: Cytokeratin 7, Cytokeratin 20.

\section{Consent}

Written consent was sought and obtained from the patient prior to publication of this article.

\section{Competing interests}

The authors declare that they have no competing interests.

\section{Authors' contributions}

SP operated on the patient, conducted the collection of the data and the literature and conceived the case report. SM was involved in collection of literature and drafting the article. RRH was the principal investigator, operated on the patient collected data and was involved in the drafting of the article.

All the authors have read and approved the final manuscript.

\section{References}

I. Smith HJ: Extrahepatic bile duct obstruction in primary carcinoma of the lung: incidence, diagnosis, and non-operative treatment. J Natl Med Assoc 1980, 72:215-220.

2. Michaud DS: Epidemiology of pancreatic cancer. Minerva Chir 2004, 59:99-III.

3. Minni F, Casadei R, Perenze B, Greco VM, Marrano N, Margiotta A, Marrano $\mathrm{Dl}$ : Pancreatic metastases: observations of three cases and review of the literature. Pancreatology 2004, 4:509-520.

4. Roland CF, van Heerden JA: Nonpancreatic primary tumors with metastasis to the pancreas. Surg Gynecol Obstet 1989, 1 68:345-347.
5. Doring $\mathrm{C}$, Lindlar F: [Clinically a primary lung carcinoma - during autopsy metastasis of a pancreatic cancer]. Med Welt 1969, 8:407-4II.

6. Z'graggen K, Fernandez-del CC, Rattner DW, Sigala H, Warshaw AL: Metastases to the pancreas and their surgical extirpation. Arch Surg 1998, 133:413-4I7.

7. Cubilla AIFP): Tumors of the Exocrine Pancreas 1980, 137:

8. Kim KH, Kim CD, Lee SJ, Lee G, Jeen YT, Lee HS, Chun HJ, Song CW, Um SH, Lee SW, Choi JH, Ryu HS, Hyun JH: Metastasis-induced acute pancreatitis in a patient with small cell carcinoma of the lung. J Korean Med Sci 1999, I4:107-109.

9. Abrams HL, Spiro R, Goldstein N: Metastases in carcinoma; analysis of 1000 autopsied cases. Cancer 1950, 3:74-85.

10. Beckles MA, Spiro SG, Colice GL, Rudd RM: Initial evaluation of the patient with lung cancer: symptoms, signs, laboratory tests, and paraneoplastic syndromes. Chest 2003, I 23:97S-104S.

I I. Galluzzi S, Payne PM: Bronchial carcinoma: a statistical study of 74 I necropsies with special reference to the distribution of blood-borne metastases. Br J Cancer 1955, 9:5 I |-527.

12. Jereczek B, Jassem J, Karnicka-Młodkowska H, Badzio A, MosAntkowiak R, Szczepek B, Chojak E, Dziadziuszko R, Lisowska B, Malak K: Autopsy findings in small cell lung cancer. Neoplasma 1996, 43:133-137.

13. Lankisch PG, Lohr A, Kunze E: [Acute metastasis-induced pancreatitis in bronchial carcinoma]. Dtsch Med Wochenschr 1987, I I 2:1335-1337.

14. Maeno T, Satoh H, Ishikawa H, Yamashita YT, Naito T, Fujiwara M, Kamma $\mathrm{H}$, Ohtsuka $M$, Hasegawa $\mathrm{S}$ : Patterns of pancreatic metastasis from lung cancer. Anticancer Res 1998, I 8:288I-2884.

15. Johnson DH, Hainsworth JD, Greco FA: Extrahepatic biliary obstruction caused by small-cell lung cancer. Ann Intern Med 1985, 102:487-490

16. Perfetti V, Markopoulos K, Maffe GC, Picheo R, Corazza GR: Juxtapapillary pancreatic metastasis with obstructive jaundice as isolated recurrence of lung adenocarcinoma. Dig Liver Dis 2008, 40:230-231.

17. Moussa A, Mitry E, Hammel P, Sauvanet A, Nassif T, Palazzo L, Malka D, Delchier JC, Buffet C, Chaussade S, Aparicio T, Lasser P, Rougier P, Lesur G: Pancreatic metastases: a multicentric study of 22 patients. Gastroenterol Clin Biol 2004, 28:872-876.

18. Nakamura E, Shimizu M, Itoh T, Manabe T: Secondary tumors of the pancreas: clinicopathological study of 103 autopsy cases of Japanese patients. Pathol Int 200 I, 5 I:686-690.

19. Crippa S, Angelini C, Mussi C, Bonardi C, Romano F, Sartori P, Uggeri F, Bovo G: Surgical treatment of metastatic tumors to the pancreas: a single center experience and review of the literature. World I Surg 2006, 30:1536-1542.

20. Jeong IB, Kim SM, Lee TH, Im EH, Huh KC, Kang YW, Choi YW: Pancreatic metastasis and obstructive jaundice in small cell lung carcinoma. Korean J Intern Med 2006, 2 I: I 32-135.

21. Liratzopoulos N, Efremidou El, Papageorgiou MS, Romanidis K, Minopoulos G], Manolas KJ: Extrahepatic biliary obstruction due to a solitary pancreatic metastasis of squamous cell lung carcinoma. Case report. J Gastrointestin Liver Dis 2006, I 5:73-75.

22. Chowhan NM, Madajewicz S: Management of metastasesinduced acute pancreatitis in small cell carcinoma of the lung. Cancer 1990, 65:|445-|448.

23. Evans AT: Necrotising pancreatitis and diabetes associated with disseminated small cell carcinoma of lung. Scott Med J 1988, 33:377.

24. Hall M, Bundred NJ, Hall AW: Oat cell carcinoma of the bronchus and acute pancreatitis. Eur J Surg Oncol 1987, 13:371-372.

25. Kubota T, lkezoe T, Harada R, Nakata H, Kobayashi M, Taguchi $H$ : [Pancreatic metastasis from lung cancer: report of an autopsy case]. Nihon Kokyuki Gakkai Zasshi 2003, 41:917-921.

26. Moazzam N, Mir A, Potti A: Pancreatic metastasis and extrahepatic biliary obstruction in squamous cell lung carcinoma. Med Oncol 2002, 19:273-276.

27. Niccolini DG, Graham JH, Banks PA: Tumor-induced acute pancreatitis. Gastroenterology 1976, 7 I: |42-145.

28. Noseda A, Gangji D, Cremer M: Acute pancreatitis as presenting symptom and sole manifestation of small cell lung carcinoma. Dig Dis Sci 1987, 32:327-331. 
29. Papagiannis A, Zarogoulidis K, Delis D, Patakas D: A 52-year-old man with a lung mass and acute abdominal pain. Chest 2000, I I 7:894-896.

30. Sakar A, Kara E, Aydede H, Ayhan S, Celik P, Yorgancioglu A: A case of a small cell lung carcinoma presenting with jaundice due to pancreatic metastasis. Tuberk Toraks 2005, 53: I8I-184.

31. Schmitt JK: Pancreatitis and diabetes mellitus with metastatic pulmonary oat-cell carcinoma. Ann Intern Med 1985, 1 03:638-639.

32. Schwarz RE, Chu PG, Grannis FW Jr: Pancreatic tumors in patients with lung malignancies: a spectrum of clinicopathologic considerations. South Med J 2004, 97:8I I-8I5.

33. Seo PJ, Kim DM, Kang MS, Lee SI, Kim H]: [A case of metastasisinduced acute pancreatitis improved by chemotherapy]. Korean J Gastroenterol 2005, 46:409-4I 2.

34. Stewart KC, Dickout WJ, Urschel JD: Metastasis-induced acute pancreatitis as the initial manifestation of bronchogenic carcinoma. Chest 1993, 104:98-100.

35. Wernecke K, Peters PE, Galanski M: Pancreatic metastases: US evaluation. Radiology 1986, I60:399-402.

36. Woo JS, Joo KR, Woo YS, Jang JY, Chang YW, Lee J 2nd, Chang R: Pancreatitis from metastatic small cell lung cancer successful treatment with endoscopic intrapancreatic stenting Korean J Intern Med 2006, 2 I:256-26I.

37. Kotan C, Er M, Ozbay B, Uzun K, Barut I, Ozgoren E: Extrahepatic biliary obstruction caused by small-cell lung cancer: a case report. Acta Chir Belg 2001, I01:190-192.

38. Le BJ, Partensky C, Glemain P, Dupas B, de Kerviller B: Pancreaticoduodenectomy for metastatic ampullary and pancreatic tumors. Hepatogastroenterology 2000, 47:540-544.

39. Patchell RA, Tibbs PA, Walsh JW, Dempsey RJ, Maruyama Y, Kryscio RJ, Markesbery WR, Macdonald JS, Young B: A randomized trial of surgery in the treatment of single metastases to the brain. $N$ Engl J Med 1990, 322:494-500.

40. Hu C, Chang EL, Hassenbusch SJ 3rd, Allen PK, Woo SY, Mahajan A Komaki R, Liao Z: Nonsmall cell lung cancer presenting with synchronous solitary brain metastasis. Cancer 2006, I06:1998-2004.

41. Koutras AK, Marangos M, Kourelis T, Partheni M, Dougenis D, Iconomou G, Vagenakis AG, Kalofonos HP: Surgical management of cerebral metastases from non-small cell lung cancer. Tumori 2003, 89:292-297.

42. Luketich JD, Martini N, Ginsberg RJ, Rigberg D, Burt ME: Successful treatment of solitary extracranial metastases from nonsmall cell lung cancer. Ann Thorac Surg 1995, 60:1609-16 II.

43. Ambrogi $\vee$, Tonini G, Mineo TC: Prolonged survival after extracranial metastasectomy from synchronous resectable lung cancer. Ann Surg Oncol 200I, 8:663-666.

44. Hirano $Y$, Oda M, Tsunezuka Y, Ishikawa N, Watanabe G: Longterm survival cases of lung cancer presented as solitary bone metastasis. Ann Thorac Cardiovasc Surg 2005, I I:40 I-404.

45. Shimizu K, Nagai K, Yoshida J, Nishimura M, Hayashi R, Yokose T: Successful management of solitary malar metastasis from lung cancer. Lung Cancer 2002, 36:337-339.

46. Kim KS, Na KJ, Kim YH, Ahn SJ, Bom HS, Cho CK, Kim HJ, Kim YI, Lim SC, Kim SO, Oh IJ, Song SY, Choi C, Kim YC: Surgically resected isolated hepatic metastasis from non-small cell lung cancer: a case report. J Thorac Oncol 2006, I:494-496.

47. Hiotis SP, Klimstra DS, Conlon KC, Brennan MF: Results after pancreatic resection for metastatic lesions. Ann Surg Oncol 2002, 9:675-679.

\section{Publish with Biomed Central and every} scientist can read your work free of charge

"BioMed Central will be the most significant development for disseminating the results of biomedical research in our lifetime. "

Sir Paul Nurse, Cancer Research UK

Your research papers will be:

- available free of charge to the entire biomedical community

- peer reviewed and published immediately upon acceptance

- cited in PubMed and archived on PubMed Central

- yours - you keep the copyright
BioMedcentral 